\title{
Tension and Compression Behaviour of Fly Ash-Lime-Gypsum Composite Mixed with Treated Tyre Chips
}

\author{
S. P. Guleria and R. K. Dutta \\ Department of Civil Engineering, National Institute of Technology, Hamirpur, Himachal Pradesh 177005, India \\ Correspondence should be addressed to R. K. Dutta, rakeshkdutta@yahoo.com
}

Received 21 January 2011; Accepted 1 March 2011

Academic Editors: Y. Lai, I. Smith, and D. Zeng

Copyright (C) 2011 S. P. Guleria and R. K. Dutta. This is an open access article distributed under the Creative Commons Attribution License, which permits unrestricted use, distribution, and reproduction in any medium, provided the original work is properly cited.

\begin{abstract}
This paper presents the results of effect of inclusion of water, sodium hydroxide and carbon tetrachloride treated tire chips on Compressive load, tensile load, axial strain, diametral strain, toughness index and post peak behaviour of the reference mix containing fly ash $+8 \%$ lime $+0.9 \%$ gypsum for a curing period varying from 7 to 180 days using three different curing methods. The results of this study revealed that the axial/diametral strain, axial/tensile load of reference mix mixed with dry tyre chip can be increased with the treatment provided on dry tyre chips. The axial/diametral strain, axial/tensile load, toughness index improves with the change in curing method and curing period. Potential use of this relatively new constructional material can be road pavement having light traffic.
\end{abstract}

\section{Introduction}

Presently, most researchers are focusing their attention to find out the good way to eliminate the wastes by using them as an alternative material so that the wastes emerging in the society can be brought into useful use. Fly ash and waste tire chips are considered two examples of such wastes. Rao and Dutta [1] reported that total number of discarded tires in India were of the order of 112 million per year. On the other hand, the dumping of fly ash is on increase due to growth of thermal plants in India. Kaniraj and Gayathri [2] reported that the production of fly ash in India will be of the order of 175 million tons by the year 2012. Thus there is a need to utilize these waste materials by mixing them together for civil engineering applications. The basic objective of this work is to study the potential and possible use of stabilized composite material for pavement which undergoes compressive loading and repeated tensile loading due to moving traffic loads. Therefore, the study of properties such as compressive loadstrain, tensile load-strain, postpeak behavior, and toughness index of pavement became important. This paper examines the effect of curing period, curing method and treatment provided on tyre chips on the compressive load- strain, tensile load-strain, postpeak behaviour and toughness index of the reference mix containing fly ash-limegypsum.

\section{Background}

Several investigations have been carried out to study the possibilities of using waste tyre chips in civil engineering applications such as in road construction [3-5] to control ground erosion [6], for stabilizing slopes [6,7] as lightweight material for backfilling in retaining structures $[3,7-12]$, as aggregates in leach beds of landfills [13-15], as an additive material to asphalt $[5,16,17]$, as limiting for freezing depth [18], as fuel [11], as fuel supplement in coal-fired boilers [14, 15], for vibration isolation [19], as cushioning foams $[14,20]$, and for low strength but ductile concrete [19]. Researchers have also undertaken various studies for the engineering properties of tyre chips alone or mixed with sand/clayey soil [3, 21-29], shear strength $[1,11,16,23,26,30-36]$. There are numerous case histories on utilization of fly ash either alone or mixed with soil, lime, gypsum, or in combination. Typically fly ash has been used for soil stabilization [37], as embankment 
material [38, 39], structural fill [40], as a replacement to cement [41], coastal land reclamation [42], roads and embankments [43], stabilization of coal pillars [44], and subsidence control [45]. Ghosh and Subbarao [46] reported that addition of $1 \%$ gypsum along with $10 \%$ lime to the fly ash enhanced the unconfined compressive strength by 36.7 times. They further reported that the improvement in unconfined compressive strength is due to fly ashlime reaction as well as the catalyzing effect of gypsum on the reaction. Ghosh and Subbarao [47] reported that the addition of small percentages of gypsum 0.5 or $1.0 \%$ to fly ash-lime mix increased the strength of compacted specimens at lower curing period (7 days) compared to only-lime-stabilized mixes. They further reported that the contribution of gypsum is significant for curing periods up to 45 days and increases with increase in gypsum content from 0.5 to $1.0 \%$. But at a higher curing period (90 days), the contribution of gypsum is comparatively less. Guleria and Dutta [48] reported that the unconfined compressive strength of fly ash $+8 \%$ lime $+0.9 \%$ gypsum mixture mixed with treated tire chips is influenced by the tyre chip content, curing period, and curing method. They further reported that treatment of dry tire chips with carbon tetrachloride, sodium hydroxide and water improves the unconfined compressive strength. Maher and Balaguru [49] reported the split tensile strength of flowable high volume fly ash-cement composite. Das et al. [50] conducted tests to determine the Brazilian tensile strength of lightly cemented sand. Tensile strength of compacted soil fly ash carbide lime mixtures was reported by Consoli et al. [51].Tensile strength is a vital parameter to judge the suitability of a stabilized fly ash when it is provided to serve as a base course material in road construction. A stabilized pavement layer is subjected to repeated tensile stresses due to traffic load, and failure is initiated due to the formation and propagation of tensile cracks [52]. The stabilized layer may also be subjected to tensile stress due to differential ground movement caused by seasonal variations and temperature gradients. Generally a recycled construction material should satisfy the requirements of strength and durability [53]. Ghosh and Subbarao [47] investigated the tensile strength of a class F fly ash stabilized with lime alone or in combination with gypsum. The effects of lime content 4, 6, and $10 \%$, gypsum content 0.5 and $1.0 \%$, and curing period up to 90 days on the tensile strength of the stabilized fly ash was highlighted. The results of this study reveal that the Brazilian tensile strength of the lime- and gypsum-stabilized fly ash mixes varied between 309 and $1,084 \mathrm{kPa}$ for 45 days of curing. Guleria and Dutta [54] reported that split tensile strength and absolute toughness (area under the tensile load-deformation curve up to failure) of fly ash + $8 \%$ lime $+0.9 \%$ gypsum mixture mixed with treated tire chips is influenced by the tyre chip content, curing period, and curing method. They further reported that treatment of tyre chips with carbon tetrachloride, sodium hydroxide, and water not only improves the split tensile strength but also significantly enhances the absolute toughness of the composite. The literatures presented above clearly indicate that there are a number of studies relating to the use of

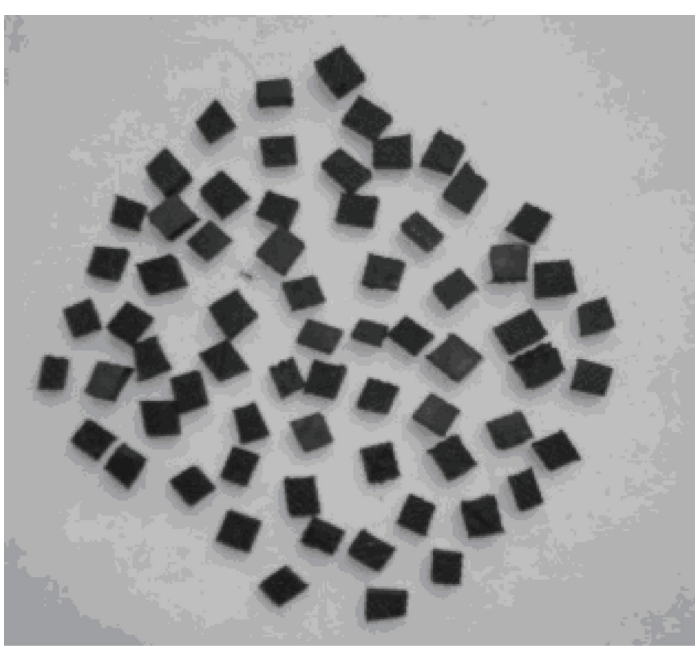

FIgURE 1: Photograph of tyre chips.

fly ash or tyre chips alone or mixed with soil, cement, lime and gypsum or in combination. However, studies relating to the compressive/tensile load-strain behaviour, postpeak behaviour in compression, and tension and toughness index of composite material consisting of a fly ash-lime-gypsum mixed with dry/treated tire chips under different curing periods and curing methods in compression and tension have not been reported so far. The present study is one such attempt to examine the effect of curing period, curing method and treatment provided on tyre chips on the compressive/tensile load-strain behaviour, postpeak behaviour in compression, and tension and toughness index of the fly ashlime-gypsum mix.

\section{Materials Used and Experimental Procedure}

The fly ash (Class F) used in the study was procured from Ropar Thermal Power Plant, Punjab, India. It had a specific gravity and dry unit weight of $2.07,9.54 \mathrm{kN} / \mathrm{m}^{3}$, respectively. Commercially available lime and gypsum were used in the study. The chemical composition, XRD, and SEM of fly ash, lime, and gypsum are reported elsewhere [55] The tire chips were derived from waste tires for the study. The tread rubber was first removed from waste tire of passenger car and was cut into strips of $10 \mathrm{~mm}$ size. Further, chips of approximately $5 \mathrm{~mm}$ size (Figure 1) were derived as per the technique reported by Rao and Dutta [1]. Further, the ratio of the maximum chip size to the diameter of the specimen is around 7; hence, the results obtained are likely be indicative of the overall behaviour for purposes of comparison. Many other researchers like Khatib et al. [56] and Segre and Joekes [57] used smaller sized tyre chips. The tyre chips were found to have specific gravity of 1.12 and average thickness of $2.7 \mathrm{~mm}$. A reference mix containing fly ash $+8 \%$ lime $+0.9 \%$ gypsum was selected for further experimental work based upon the compaction studies reported elsewhere [55]. The quantity of gypsum was 
restricted to $0.9 \%$ as higher percentage may have deleterious effects [58]. Ghosh and Subbarao [59] have also restricted the content of gypsum to $1 \%$. A metallic mould having size $38 \mathrm{~mm}$ inner diameter $\times 76 \mathrm{~mm}$ long and $38 \mathrm{~mm}$ inner diameter $\times 19 \mathrm{~mm}$ long, with additional detachable collars, was used to prepare specimens for compressive and tensile strength tests. In order to keep the total volume as constant, fly ash equivalent to the weight of tire chips (5\% corresponding to the dry weight of fly ash) was removed and replaced with dry tire chips. The quantity of $8 \%$ lime and $0.9 \%$ gypsum by reduced dry weight of fly ash was then mixed thoroughly, and the required quantity of water (corresponding to optimum moisture content (OMC)) was added to the mix in the first series of experiments (designated as C1). For the subsequent series of experiments tyre chips were dipped for 20 minutes in water (designated as C2), sodium hydroxide (designated as C3), and carbon tetra chloride (designated as $\mathrm{C} 4$ ) solution before adding them to the reference mix. The quantity of water/solution equivalent to the weight of the absorbed water/solution by the tyre chips was deducted from the required quantity of water (corresponding to OMC) to facilitate compaction. To ensure uniform compaction, specimen was compressed statically from both ends till the specimen just reached the dimensions of the mould. Then the specimen was extracted with the hydraulic jack and was allowed to dry for one day at room temperature. The one-day dried specimens were cured for 7, 28, 90, and 180 days using three different curing methods. In the first method (designated as M1), the specimen was placed in an air tight polythene bag which was then placed in a dessicator and was closely tight with a lid. The dessicator was then placed in the laboratory at room temperature. In the second method of curing (designated as M2), the one-day dried specimen was put in the burlap for curing. The burlap was kept wet by sprinkling water regularly. The third method curing (designated as M3), the specimen was placed in a container filled with water and having a provision of inflow and outflow of water for curing. For easy reference and identification of specimen, specific codification was used. Specimens containing only reference mix (without tyre chips) were designated by sixletter codification. The first letter of codification $\mathrm{R}$ indicates reference mix, the next three digit numbers and third two digit numbers indicate curing period and the curing method, respectively. For reference mix with tire chips, nine-letter codification schemes were used. The first two digits of the codification indicate tire chip content and the next three and consequently the next two digit numbers indicate curing period, tire treatment, and curing method, respectively. For example, number $05028 \mathrm{C} 3 \mathrm{M} 2$ will indicate addition of $5 \%$ tire chips, 28 -day curing period, sodium hydroxidetreated tire chips and cured by burlap, respectively. The compressive strength and tensile tests were conducted as per IS 4332: Part 5: (1970) (reaffirmed on 03/2001) and IS: 10082-1981, respectively. A proving ring of $2 \mathrm{KN}$ and $5 \mathrm{KN}$ capacity was used for testing specimens of 7 and 28 days and for 90 and 180 days respectively. A strain rate of $0.04 \mathrm{~mm} / \mathrm{min}$ was maintained for compressive and tensile strength tests.

\section{Results and Discussion}

4.1. Compression Behaviour. The axial load-axial strain behavior of the reference mix mixed with 5\% dry/treated tire chips and cured for 7 days with curing methods M1, M2, and M3 is shown in Figure 2. The values of compressive axial load and corresponding axial strain of the reference mix with and without $5 \%$ dry/treated tire chips are given in Tables 1 and 2 respectively.

4.1.1. Compressive Axial Load. A study of Figures 2(a), 2(b), and 2(c) and Table 1 reveals that the peak axial load of reference mix mixed with tire chip increases with the change in treatment provided on tire chips with all the curing methods. A further examination of Figures 2(a), 2(b), and 2 (c) and Table 1 reveals an increase in the peak axial load of reference mix mixed with dry/treated tire chips with the change in the curing method and increase in curing period. Table 1 further reveals a decrease in the peak axial load of reference mix mixed with dry/treated tire chips in comparison to the reference mix without tire chips. For example, an axial load of R007M1 was $0.09 \mathrm{kN}$ which decreased to $0.03 \mathrm{kN}$ with the inclusion of $5 \% \mathrm{C} 1$ tire chips in the reference mix. Similar decrease in axial load was observed with the inclusion of other treated tire chips and at other curing methods. Thus, it can be concluded that the peak axial load of reference mix mixed with 5\% dry tire chip increases with the treatment provided on dry tire chips and was the highest with the carbon tetra chloride followed by sodium hydroxide and water, respectively. The peak axial load also increased with the change in curing method and with the increase in the curing period.

4.1.2. Compressive Axial Strain. A study of Figure 2 reveals that the axial strain increases with the change in the treatment provided on the tire chips. For example, for specimen $05007 \mathrm{C} 1 \mathrm{M} 3$, the axial strain was $3.10 \%$ which increased to $4.64 \%, 5.42 \%$, and $6.19 \%$ with the change in treatment to C2, C3, and C4, respectively. Similar increase in axial strain was observed with other curing methods (M1, $\mathrm{M} 2$, and M3). Table 2 shows the variation of axial strain of reference mix with and without $5 \%$ dry/treated tire chips at $7,28,90$, and 180 days curing with M1, M2, and M3 curing methods. A close examination of Table 2 reveals an increase in the axial strain of reference mix mixed with $5 \%$ dry/treated tire chips with the change in curing method. For example, for specimen $05007 \mathrm{C} 1 \mathrm{M} 1$, the axial strain was $1.54 \%$ which increased to $3.09 \%$ with the change in curing method from M1 to M2. The value of axial strain further increased to $3.10 \%$ with the change in curing method from M1 to M3. Similar increase in axial strain was observed with the inclusion of $5 \%$ dry/treated tire chips when cured for $28,90,180$ days of curing, respectively. Table 2 further reveals that the axial strain increases with the increase in curing period. For example, an axial strain of specimen 05007C1M1 was $1.54 \%$ which increased to $2.32 \%, 2.42 \%$ and $3.09 \%$ with the change in curing period to 28,90 , and 180 days, respectively. Similar increase in axial strain was observed 


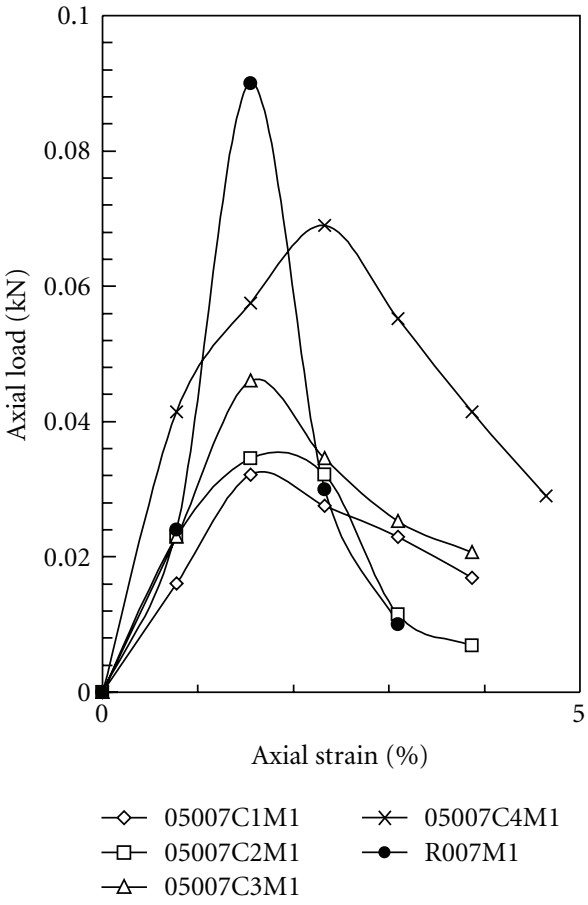

(a)

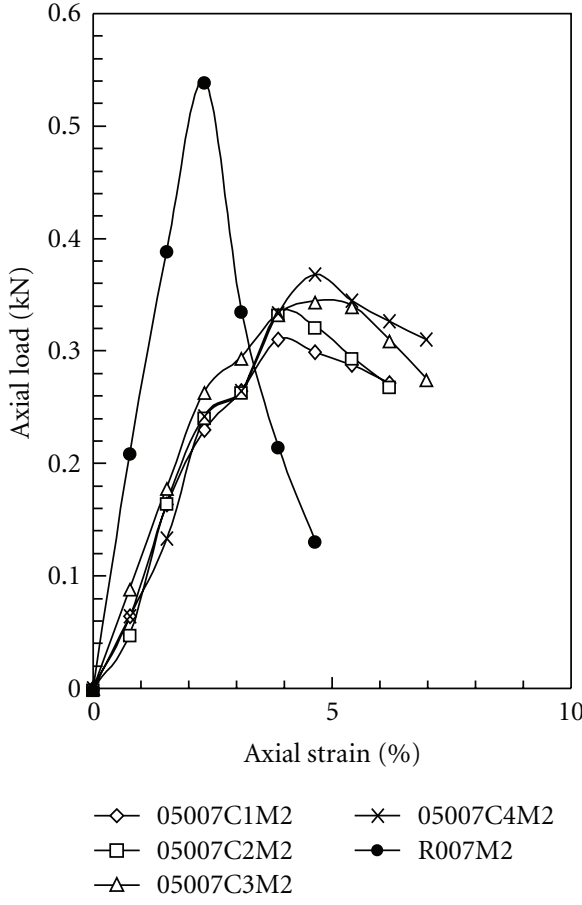

(b)

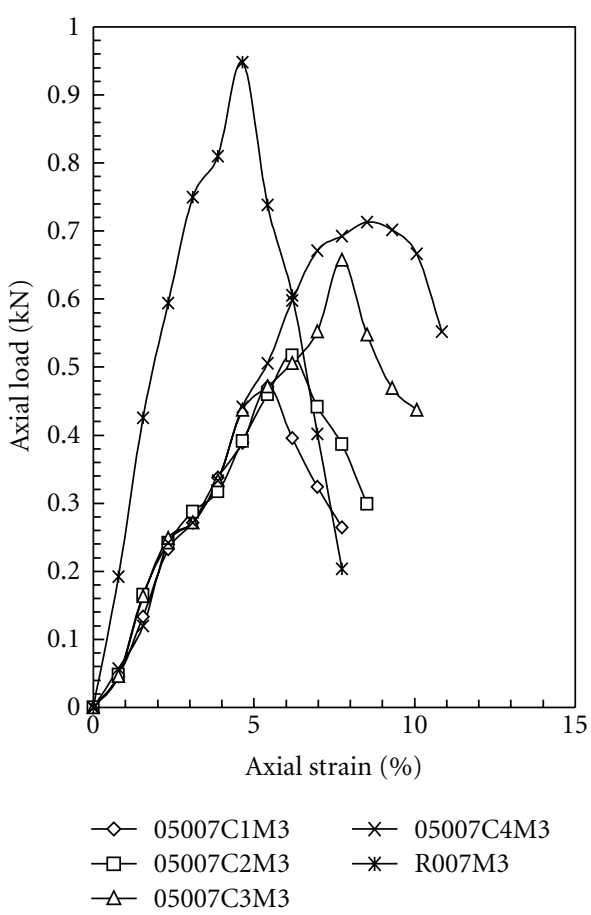

(c)

Figure 2: Axial load-axial strain behavior of reference mix with and without $5 \%$ dry/treated tire chips cured for 7 days with curing methods (a) M1, (b) M2, and (c) M3.

with other tire chip treatment (C2, C3 and C4) and curing methods (M1, M2 and M3) as evident from Table 2. Thus from the above discussion, it can be concluded that the axial strain of reference mix mixed with 5\% dry tire chip can be increases with treatment provided on the dry tire chips.
The increase in axial strain was the highest with the carbon tetrachloride treatment provided on dry tire chips followed by sodium hydroxide and water, respectively. The axial strain also increased with the change in the curing method and with the increase in the curing period. 
TABLE 1: Variation of peak compressive axial load $(\mathrm{kN})$ of the reference mix with and without 5\% dry/treated tire chips cured for $7,28,90$, and 180 days with M1, M2, and M3 methods of curing.

\begin{tabular}{|c|c|c|c|c|c|c|c|c|c|c|c|c|c|c|c|}
\hline \multirow{2}{*}{ Curing period } & \multicolumn{5}{|c|}{ M1 } & \multicolumn{5}{|c|}{ M2 } & \multicolumn{5}{|c|}{ M3 } \\
\hline & $\mathrm{C} 1$ & $\mathrm{C} 2$ & $\mathrm{C} 3$ & $\mathrm{C} 4$ & $\mathrm{R}$ & $\mathrm{C} 1$ & $\mathrm{C} 2$ & $\mathrm{C} 3$ & $\mathrm{C} 4$ & $\mathrm{R}$ & $\mathrm{C} 1$ & $\mathrm{C} 2$ & $\mathrm{C} 3$ & $\mathrm{C} 4$ & $\mathrm{R}$ \\
\hline 7 & 0.03 & 0.034 & 0.04 & 0.06 & 0.09 & 0.31 & 0.33 & 0.34 & 0.36 & 0.54 & 0.47 & 0.51 & 0.65 & 0.71 & 0.94 \\
\hline 28 & 0.20 & 0.24 & 0.26 & 0.32 & 0.48 & 0.34 & 0.41 & 0.47 & 0.69 & 0.81 & 0.51 & 0.57 & 0.69 & 0.79 & 0.99 \\
\hline 90 & 0.44 & 0.52 & 0.6 & 0.68 & 0.79 & 0.78 & 0.80 & 0.87 & 0.99 & 1.10 & 0.88 & 1.18 & 1.23 & 1.25 & 1.35 \\
\hline 180 & 0.46 & 0.53 & 0.63 & 0.75 & 0.85 & 0.82 & 0.82 & 0.94 & 1.07 & 1.38 & 0.91 & 1.20 & 1.26 & 1.30 & 1.40 \\
\hline
\end{tabular}

TABLE 2: Variation of axial strain (\%) at failure of the reference mix with and without $5 \%$ dry/treated tire chips cured for $7,28,90$, and 180 days with M1, M2, and M3 methods of curing.

\begin{tabular}{|c|c|c|c|c|c|c|c|c|c|c|c|c|c|c|c|}
\hline \multirow{2}{*}{ Curing period } & \multicolumn{5}{|c|}{ M1 } & \multicolumn{5}{|c|}{ M2 } & \multicolumn{5}{|c|}{ M3 } \\
\hline & $\mathrm{C} 1$ & C2 & C3 & $\mathrm{C} 4$ & $\mathrm{R}$ & $\mathrm{C} 1$ & $\mathrm{C} 2$ & C3 & $\mathrm{C} 4$ & $\mathrm{R}$ & $\mathrm{C} 1$ & $\mathrm{C} 2$ & C3 & $\mathrm{C} 4$ & $\mathrm{R}$ \\
\hline 7 & 1.54 & 2.32 & 3.09 & 3.10 & 1.35 & 3.09 & 3.87 & 4.64 & 5.4 & 2.32 & 3.10 & 4.64 & 5.42 & 6.19 & 2.39 \\
\hline 28 & 2.32 & 3.09 & 3.10 & 3.87 & 1.40 & 3.87 & 4.6 & 5.4 & 5.42 & 3.87 & 3.87 & 5.42 & 5.48 & 6.97 & 3.09 \\
\hline 90 & 2.42 & 3.10 & 3.87 & 4.64 & 2.32 & 4.64 & 4.64 & 5.48 & 5.48 & 3.09 & 4.64 & 6.19 & 6.23 & 7.74 & 3.87 \\
\hline 180 & 3.09 & 3.87 & 4.64 & 5.42 & 2.39 & 5.42 & 5.42 & 6.19 & 6.23 & 4.64 & 5.42 & 6.23 & 6.97 & 8.26 & 4.67 \\
\hline
\end{tabular}

4.1.3. Postpeak Compression Behavior. To better understand the tire chips toughening characteristics in the postpeak region, the load axis of the load-strain diagram was normalized with respect to the peak axial load, and the axial strain axis was normalized with respect to the axial strain occurring at the peak axial load. The variation of normalized load with normalized strain for reference mix with and without $5 \%$ dry/treated tire chips and cured for 7 days with M1, M2 and M3 is shown in Figure 3. An examination of Figure 3 reveals a sharp drop in the postpeak region of reference mix without tire chips whereas the specimen of reference mix mixed with 5\% dry/treated tire chips were observed to follow a gradual decline after attaining the peak in the normalized load-strain curve. Similar behavior of reference mix with and without dry/treated tire chips was observed with other curing methods and at 28, 90, and 180 days of curing. Thus from the above discussion, it can be concluded that inclusion of dry/treated tire chips in reference mix improves the postpeak behaviour in compression.

4.1.4. Toughness Index in Compression. In order to focus only on the postpeak behavior and to compare the performance of the reference mix mixed with dry/treated tire chips with that of the elastic-perfectly material, a dimensionless toughness index (T1) as reported by Sobhan and Mashnad [52] was calculated using the following formula:

$$
\mathrm{T} 1=\frac{\left(A_{d}-A_{p}\right)}{\left(\left(d / d_{p}\right)-1\right)},
$$

where $d_{p}$ : strain at peak axial load; $d$ : any strain that is greater than the $d_{p}$ value; $A_{p}$ : area under the normalized curve up to the peak; and $A_{d}$ : area under the normalized curve up to the strain ratio $d / d_{p}$. The T1 value calculated in this way compares the performance of the reference mix mixed with 5\% dry/treated tire chips with that of a elastic-perfectly material, for which the T1 is unity. On the other hand, T1 is zero for an ideal brittle material. Figure 4 shows the variation of toughness index of reference mix with and without 5\% dry/treated tire chips cured with M1, M2, and M3 methods of curing. A study of Figure 4(a) reveals that the toughness index of reference mix mixed with dry tire chip increases with the change in the treatment provided on tire chips. For example, for specimen $05007 \mathrm{C} 1 \mathrm{M} 1$, the toughness index was 0.606 , which increased to 0.622 when the treatment of tire chip was changed to $\mathrm{C} 2$ for the same specimen. The value of toughness index of the same specimen further increased to 0.675 and 0.688 with the change in tire chip treatment to $\mathrm{C} 3$ and $\mathrm{C} 4$, respectively. Similar increase in toughness index was observed with other curing methods and other curing periods. A further examination of Figures 4(a), 4(b), and $4(\mathrm{c})$, reveals an increase in the toughness index with the change in the curing method. For example, for the specimen $05007 \mathrm{C} 1 \mathrm{M} 1$, the toughness index was 0.606 which increased to 0.717 when the curing method was changed from M1 to M2. The value of toughness index of the same specimen further increased to 0.770 with the change in curing method to M3. Similar increase in toughness index was observed with other treated tire chips. A study of Figures 4(a), 4(b) and 4(c) further reveals an increase in toughness index with the increase in curing period. For example, for specimen $05007 \mathrm{C} 1 \mathrm{M} 1$, the toughness index of 0.606 increased to $0.714,0.810$ and 0.815 after 28,90 , and 180 days of curing, respectively. A similar increase in toughness index was observed with other treated tire chips and curing methods. A close examination of Figures 4(a), 4(b) and 4(c) reveals an increase in the toughness index with the inclusion of $5 \%$ dry/treated tire chips in the reference mix. For example, the toughness index of R007M1 was 0.311 which 


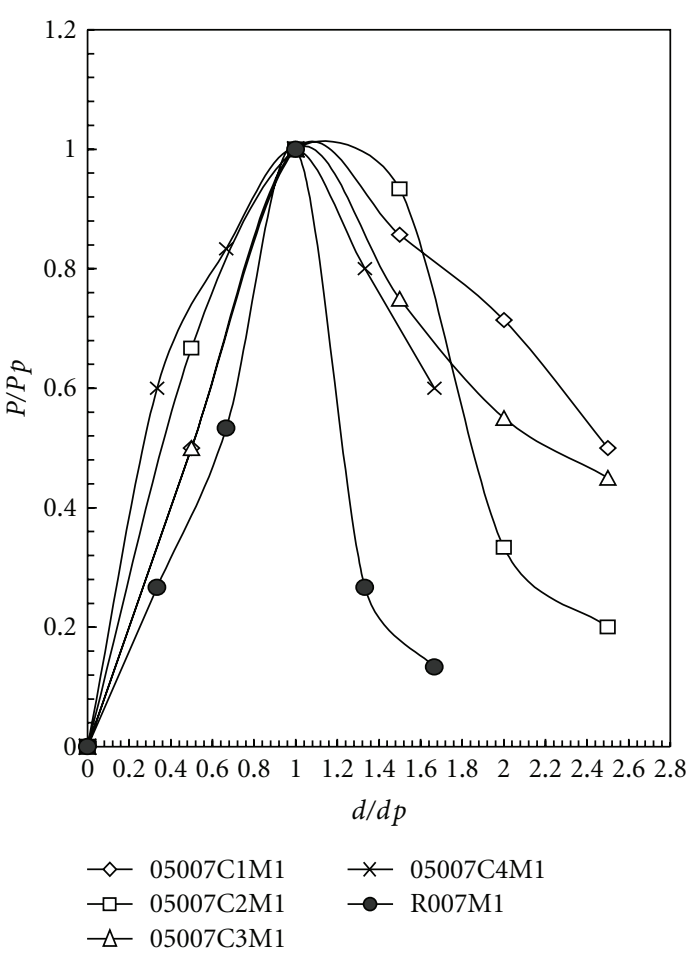

(a)

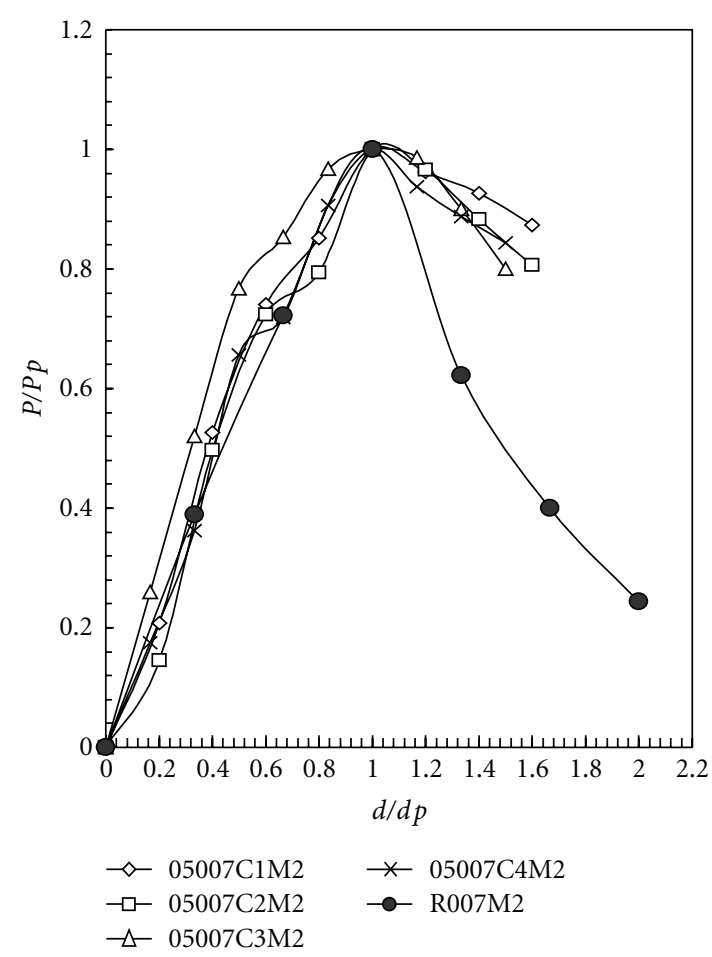

(b)

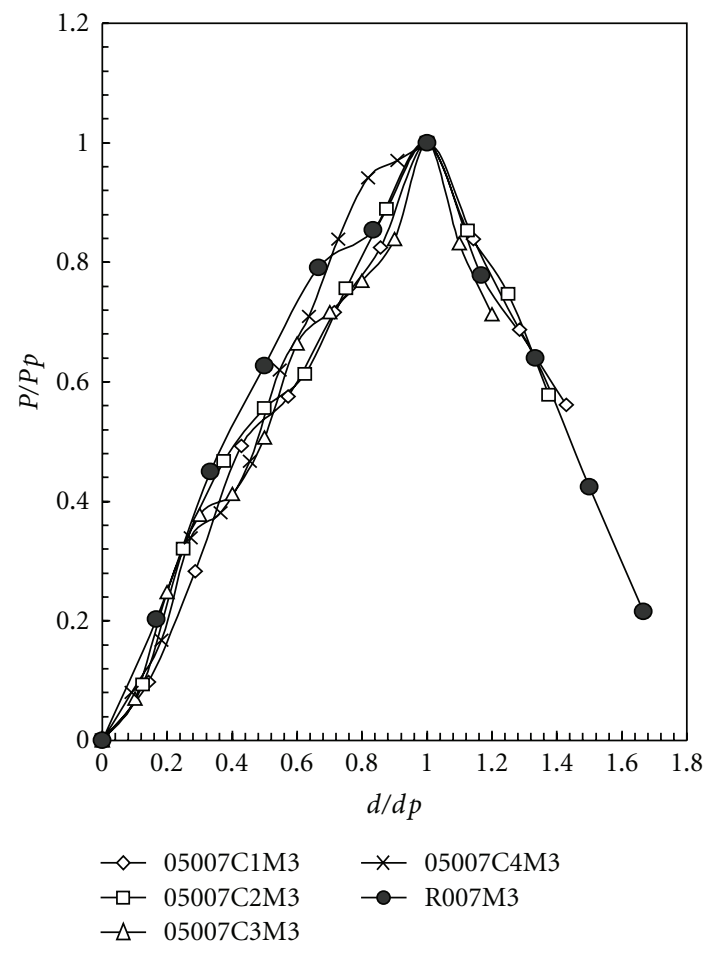

(c)

Figure 3: Normalized axial load-axial strain behavior of reference mix mixed with and without 5\% dry/treated tire chips cured for 7 days with curing methods (a) M1, (b) M2, and (c) M3. 


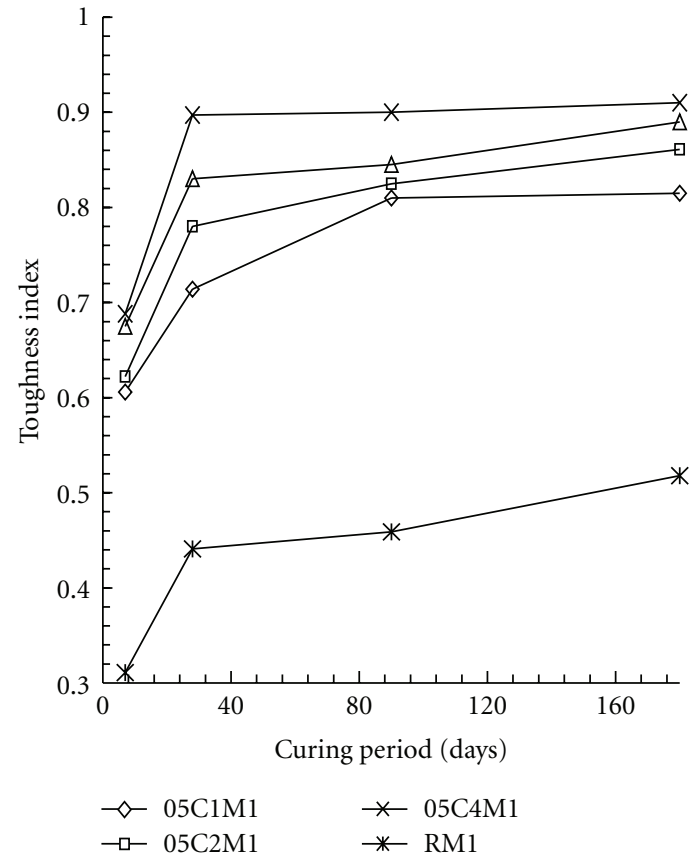

(a)

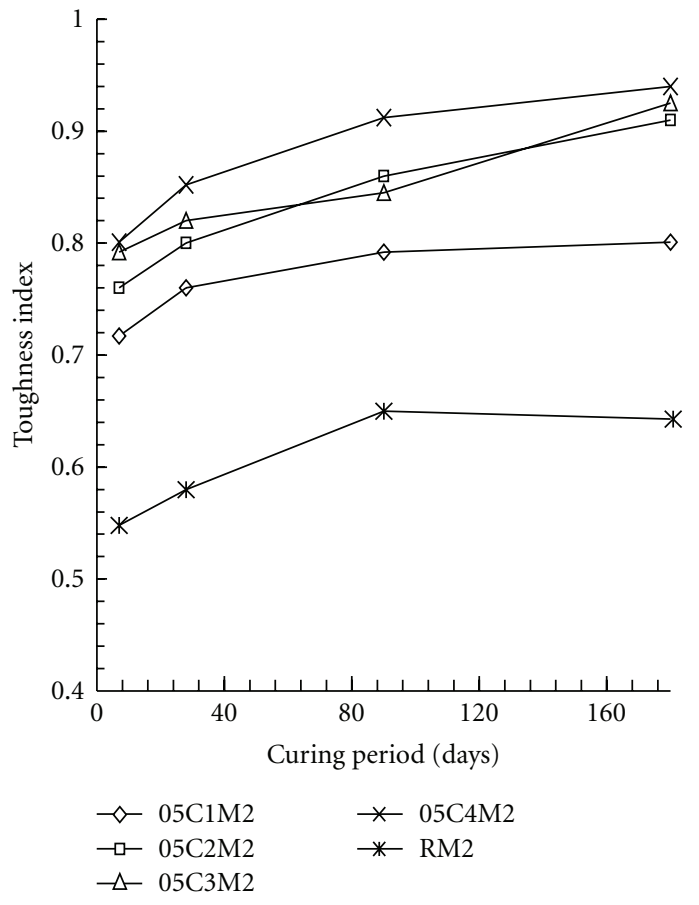

(b)

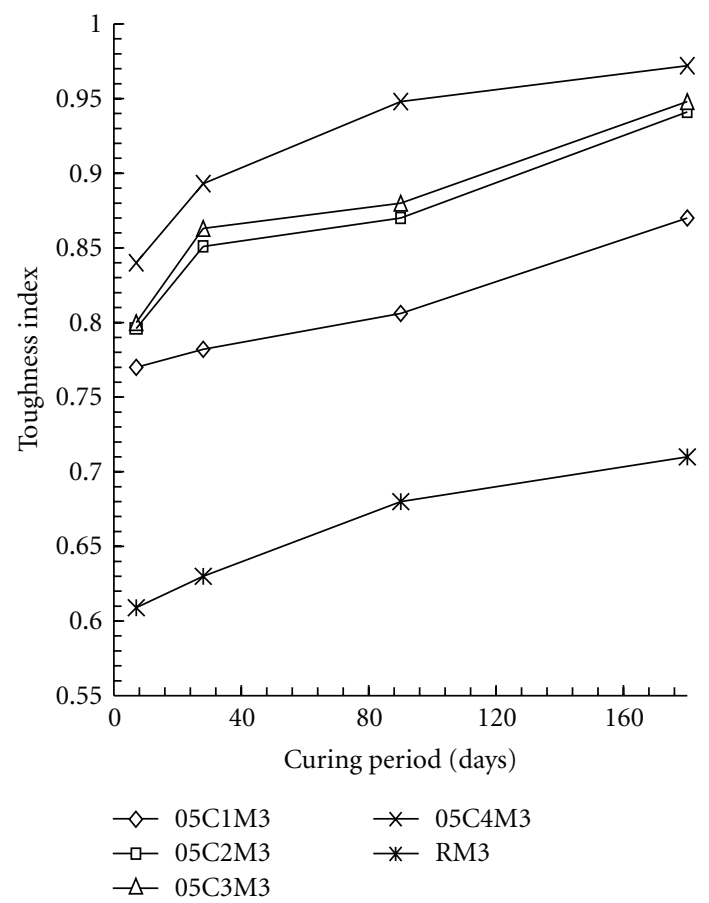

(c)

FIGURE 4: Variation of toughness index in compression with curing period of the reference mix with and without $5 \%$ dry/treated tire chips cured with curing methods (a) M1, (b) M2, and (c) M3.

increased to 0.606 with the inclusion of $5 \%$ dry tire chips in the reference mix. Similar increase in toughness index was observed with the inclusion of other treated tire chips and with other curing methods. Thus from the above discussion it can be concluded that inclusion of $5 \%$ dry/treated tire chips improves the toughness characteristics of the reference mix under compression. The toughness characteristics of reference mix with and without $5 \%$ dry/treated tire chips increases with the change in curing method and with the increase in the curing period. 


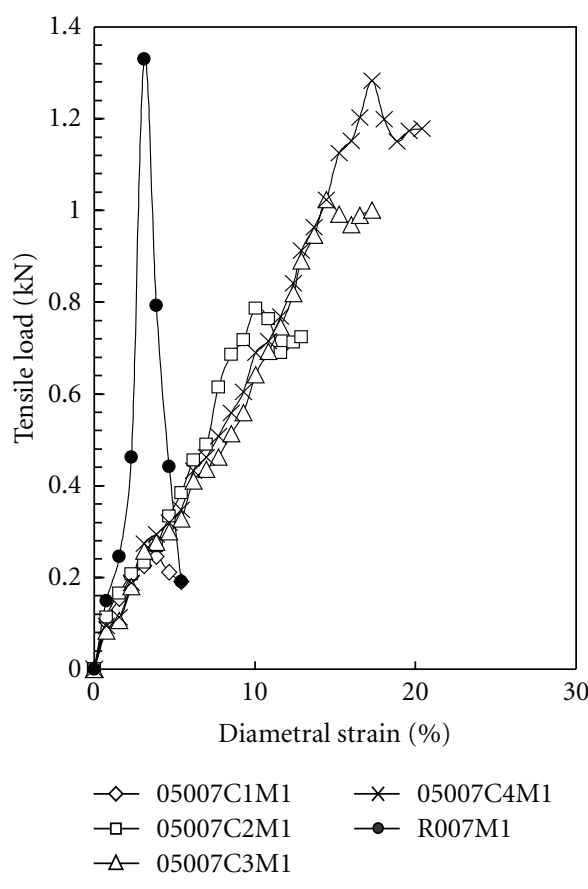

(a)

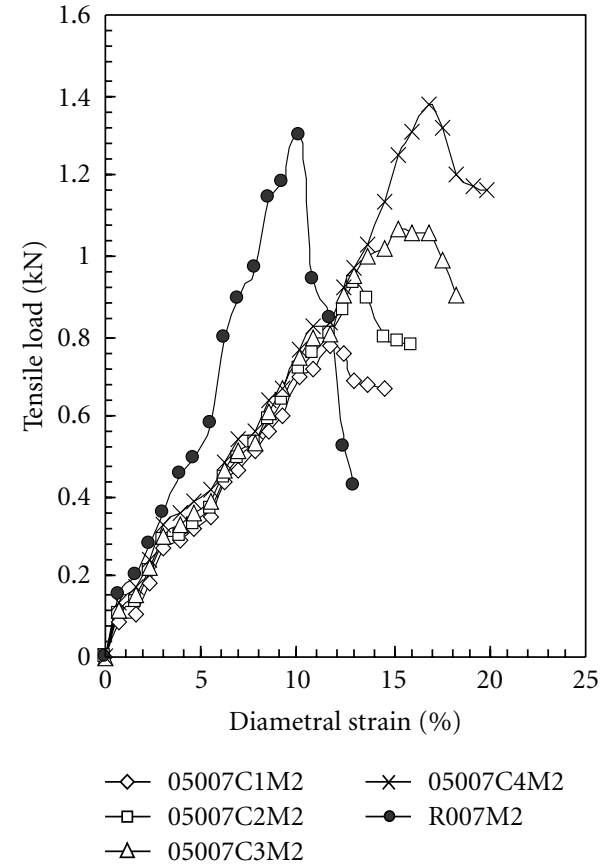

(b)

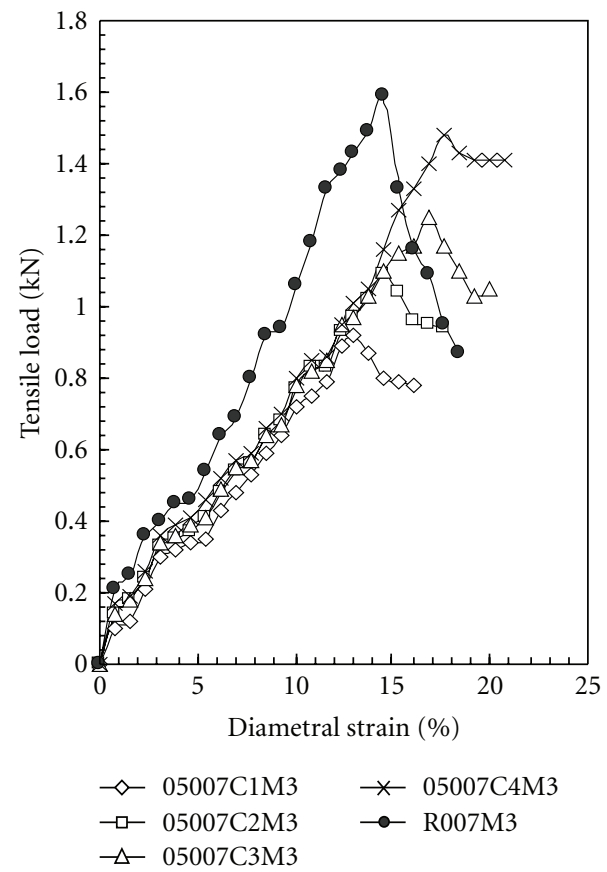

(c)

Figure 5: Tensile load-diametral strain of reference mix and with 5\% dry/treated tire chips cured for 7 days with curing methods (a) M1, (b) M2, and (c) M3.

4.2. Tension Behavior. The tensile load-diametral strain of the reference mix with and without 5\% dry/treated tire chips cured for 7 days with curing methods M1, M2 and M3 is shown in Figure 5. The peak tensile load and corresponding diametral strain (\%) of reference mix with and without 5\% dry/treated tire chips cured with curing methods M1, M2, M3 at 7, 28, 90, and 180 days are shown in Tables 3 and 4, respectively.
4.2.1. Tensile Load. A study of Figures 5(a), 5(b), and 5(c) and Table 3 reveals that peak tensile load of reference mix mixed with dry tire chip increases with the change in treatment provided on tire chips with all the curing methods. A further examination of Figures 5(a), 5(b), and 5(c) and Table 3 reveals an increase in the tensile load of reference mix mixed with dry/treated tire chips with the increase in curing period and change in the curing method. Table 3 
TABLE 3: Variation of peak tensile load $(\mathrm{kN})$ of the reference mix with and without $5 \%$ dry/treated tire chips and cured for $7,28,90$, and 180 days with M1, M2, and M3 methods of curing.

\begin{tabular}{|c|c|c|c|c|c|c|c|c|c|c|c|c|c|c|c|}
\hline \multirow{2}{*}{ Curing period } & \multicolumn{5}{|c|}{ M1 } & \multicolumn{5}{|c|}{ M2 } & \multicolumn{5}{|c|}{ M3 } \\
\hline & $\mathrm{C} 1$ & $\mathrm{C} 2$ & $\mathrm{C} 3$ & $\mathrm{C} 4$ & $\mathrm{R}$ & $\mathrm{C} 1$ & $\mathrm{C} 2$ & C3 & $\mathrm{C} 4$ & $\mathrm{R}$ & $\mathrm{C} 1$ & $\mathrm{C} 2$ & $\mathrm{C} 3$ & $\mathrm{C} 4$ & $\mathrm{R}$ \\
\hline 7 & 0.24 & 0.78 & 1.02 & 1.28 & 1.32 & 0.77 & 0.92 & 1.06 & 1.37 & 1.40 & 0.92 & 1.09 & 1.16 & 1.48 & 1.59 \\
\hline 28 & 1.05 & 1.38 & 1.77 & 1.99 & 2.04 & 1.61 & 2.3 & 2.58 & 2.70 & 2.75 & 1.84 & 3.50 & 3.67 & 4.08 & 4.14 \\
\hline 90 & 1.20 & 1.54 & 2.08 & 2.26 & 2.47 & 1.73 & 2.58 & 2.68 & 2.87 & 2.93 & 2.11 & 3.73 & 4.13 & 4.27 & 4.5 \\
\hline 180 & 1.44 & 1.80 & 2.09 & 2.48 & 2.60 & 1.94 & 2.57 & 2.80 & 3.25 & 3.40 & 2.36 & 3.79 & 4.13 & 4.37 & 4.87 \\
\hline
\end{tabular}

TABLE 4: Variation of diametral strain (\%) at failure of the reference mix with and without 5\% dry/treated tire chips and cured for 7, 28, 90 , and 180 days with M1, M2, and M3 methods of curing.

\begin{tabular}{|c|c|c|c|c|c|c|c|c|c|c|c|c|c|c|c|}
\hline \multirow{2}{*}{ Curing period } & \multicolumn{5}{|c|}{ M1 } & \multicolumn{5}{|c|}{ M2 } & \multicolumn{5}{|c|}{ M3 } \\
\hline & $\mathrm{C} 1$ & $\mathrm{C} 2$ & $\mathrm{C} 3$ & $\mathrm{C} 4$ & $\mathrm{R}$ & $\mathrm{C} 1$ & $\mathrm{C} 2$ & $\mathrm{C} 3$ & $\mathrm{C} 4$ & $\mathrm{R}$ & $\mathrm{C} 1$ & $\mathrm{C} 2$ & $\mathrm{C} 3$ & $\mathrm{C} 4$ & $\mathrm{R}$ \\
\hline 7 & 3.87 & 10.0 & 14.4 & 17.2 & 3.09 & 8.51 & 10.0 & 12.9 & 14.4 & 9.29 & 10.0 & 12.9 & 14.4 & 15.4 & 9.29 \\
\hline 28 & 6.19 & 9.29 & 10.1 & 12.9 & 6.19 & 10.1 & 14.4 & 17.5 & 17.9 & 11.6 & 11.6 & 17.5 & 17.9 & 18.5 & 12.9 \\
\hline 90 & 6.96 & 10.0 & 12.3 & 13.1 & 6.96 & 12.3 & 17.5 & 18.5 & 19.4 & 11.9 & 13.1 & 14.4 & 17.5 & 18.6 & 12.3 \\
\hline 180 & 7.74 & 11.6 & 13.1 & 17.8 & 11.9 & 17.5 & 18.5 & 19.4 & 20.1 & 17.2 & 18.5 & 19.4 & 21.6 & 24 & 17.5 \\
\hline
\end{tabular}

further reveals a decrease in the peak tensile load of reference mix mixed with dry/treated tire chips in comparison to the reference mix without tire chips. For example, peak tensile load of R007M1 was $1.32 \mathrm{kN}$, which decreased to $0.24 \mathrm{kN}$ with the inclusion of $5 \% \mathrm{C} 1$ tire chips in the reference mix. Similar decrease in peak tensile load was observed with the inclusion of other treated tire chips and at other curing methods. Thus it can be concluded that the peak tensile load of the reference mix mixed with $5 \%$ dry tire chips increased with the treatment and was the highest with the inclusion of treated tire chips with carbon tetrachloride followed by sodium hydroxide and water, respectively. The peak tensile load also increases with the change in curing method and with the increase in the curing period.

4.2.2. Diametral Strain. The study of the Figure 5(a) also reveals an increase in the diametral strain with the change in the treatment provided on the tire chips. For example, for specimen $05007 \mathrm{C} 1 \mathrm{M} 1$, the diametral strain was $3.87 \%$ which increased to $10.0 \%, 14.4 \%$ and $17.2 \%$ with the change in the treatment from C1 to C2, C3 and C4, respectively. Similar increase in diametral strain was observed with other curing methods M2 and M3 and at other curing periods as evident from Figures 5(b) and 5(c). A close examination of Figures 5(a), 5(b) and 5(c), also reveals an increase in the diametral strain of reference mix mixed with $5 \%$ dry/treated tire chips with the change in curing methods. For example, for specimen $05007 \mathrm{C} 1 \mathrm{M} 1$, the diametral strain of was $3.87 \%$ which increased to $8.51 \%$ with the change in curing method from M1 to M2. The diametral strain further increased to $10.0 \%$ with the change in curing method from M1 to M3. Table 4 further reveals an increase in diametral strain with the increase in curing period. For example, the diametral strain of specimen $05007 \mathrm{C} 1 \mathrm{M} 1$ was $1.54 \%$ which increased to a value of $6.19 \%, 6.96 \%$ and $7.74 \%$ after 28,90 , and 180 days of curing, respectively. Similar increase in diametral strain was observed with other treated tire chips and curing methods as evident fro Table 4. Thus from the above discussion, it can be concluded that the treatment of tire chips increases the diametral strain of reference mix mixed with $5 \%$ dry tire chip. The increase in diametral strain was the highest with the treatment of dry tire chips provided with carbon tetra chloride followed by sodium hydroxide and water, respectively. The diametral strain also increases with the change in curing method and with the increase in the curing period.

4.2.3. Postpeak Tensile Behavior. In order to study the tire chips toughening characteristics in the postpeak region, the tensile load and diametral strain axis were normalized as per the procedure mentioned in the Section 4.1.3. The variation of normalized tensile load with normalized diametral strain for reference mix with and without $5 \%$ dry/treated tire chips cured for 7 days with curing methods M1, M2 and M3 is shown in Figure 6. An examination of Figure 6(a) reveals a sharp drop in the postpeak region of reference mix without tire chips whereas the specimen of reference mix mixed with $5 \%$ dry/treated tire chips were observed to follow a gradual decline after attaining the peak in the normalized tensile load-diametral strain curve. Similar behavior of reference mix with and without $5 \%$ dry/treated tire chips was observed with other curing methods and curing periods. Thus from the above discussion, it can be concluded that inclusion of $5 \%$ dry/treated tire chips in reference mix improves the postpeak behaviour of reference mix in tension.

4.2.4. Toughness Index in Tension. In order to focus only on the postpeak tensile behavior and to compare the performance of the reference mix mixed with 5\% dry/treated tire chips with that of an elastic-perfectly material, a dimensionless toughness index (T1) as per the procedure 


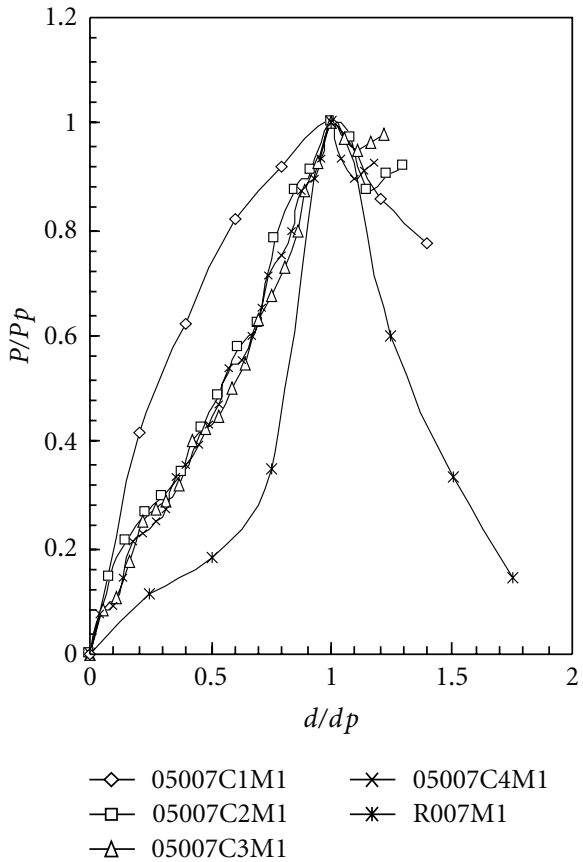

(a)

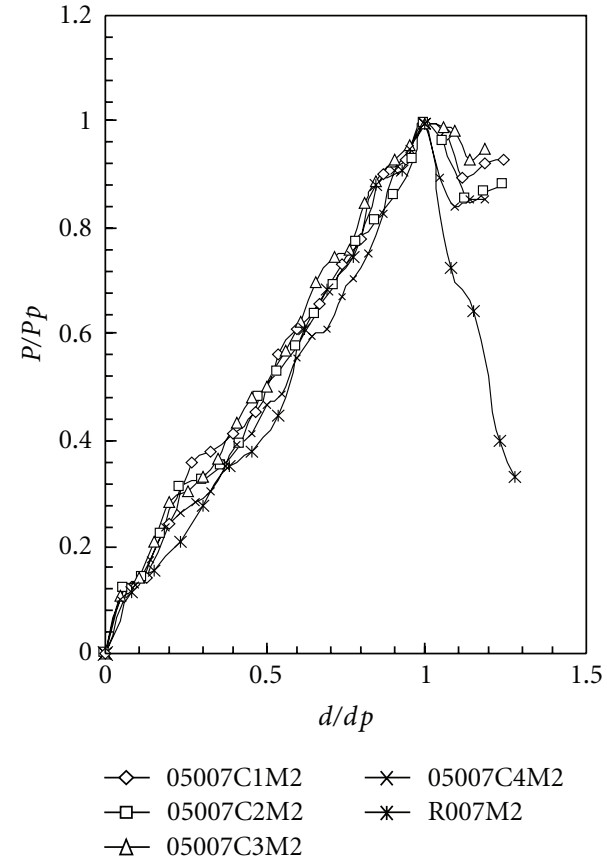

(b)

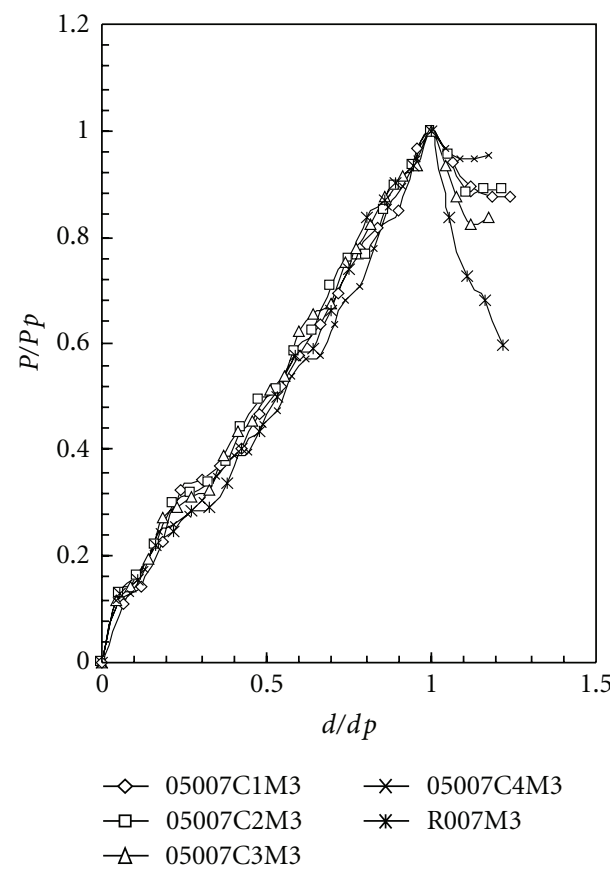

(c)

FIGURE 6: Normalized tensile load-diametral strain behavior of reference mix mixed with and without 5\% dry/treated tire chips cured for 7 days with curing method (a) M1, (b) M2, (c) and M3.

mentioned in Section 4.1.4 was calculated, and the results are shown in Figure 7. A study of Figure 7(a) reveals that the toughness index of reference mix mixed with dry tire chip increases with the change in the treatment provided on tire chips. For example, for specimen $05007 \mathrm{C} 1 \mathrm{M} 1$, the toughness index was 0.87 , which increased to 0.862 when the treatment of tire chip was changed to $\mathrm{C} 2$ for the same specimen.
The value of toughness index of the same specimen further increased to 0.874 and 0.896 with the change in tire chip treatment to $\mathrm{C} 3$ and $\mathrm{C} 4$, respectively. Similar increase in toughness index was observed with other curing methods and other curing period. A further examination of Figures 7(a), 7(b), and 7(c) reveals an increase in the toughness index with the change in the curing method. For example, for the 


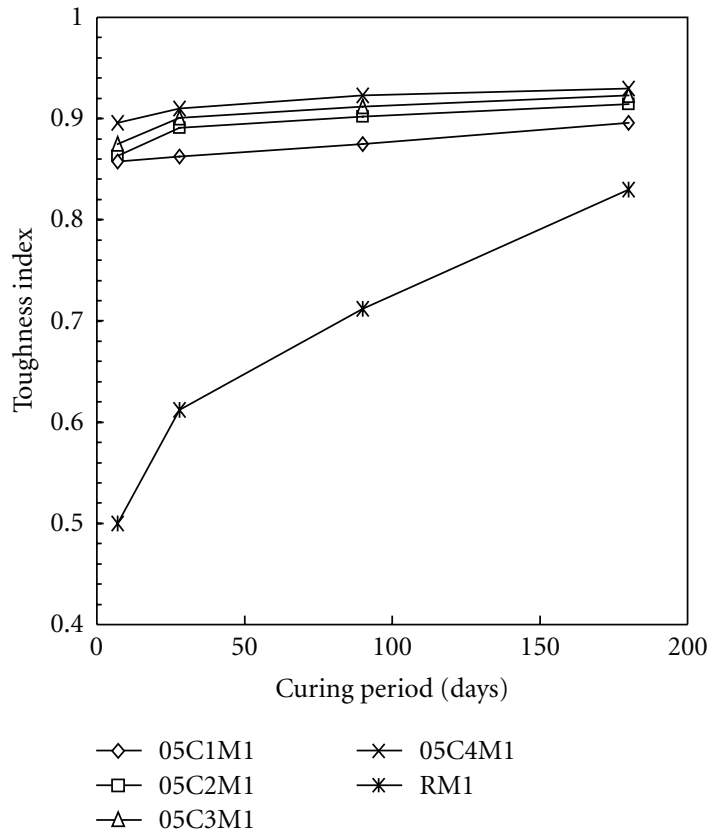

(a)

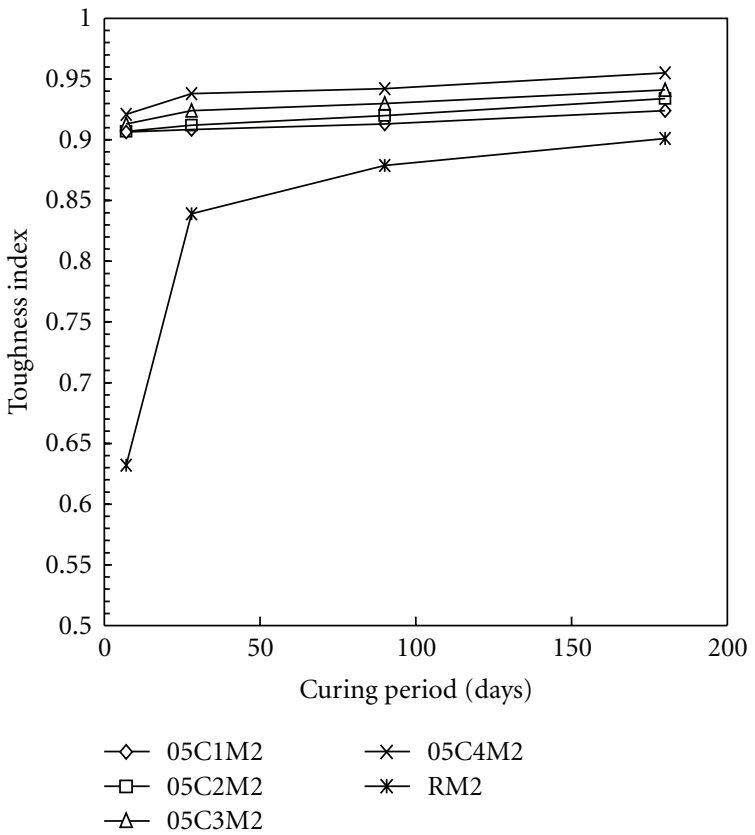

(b)

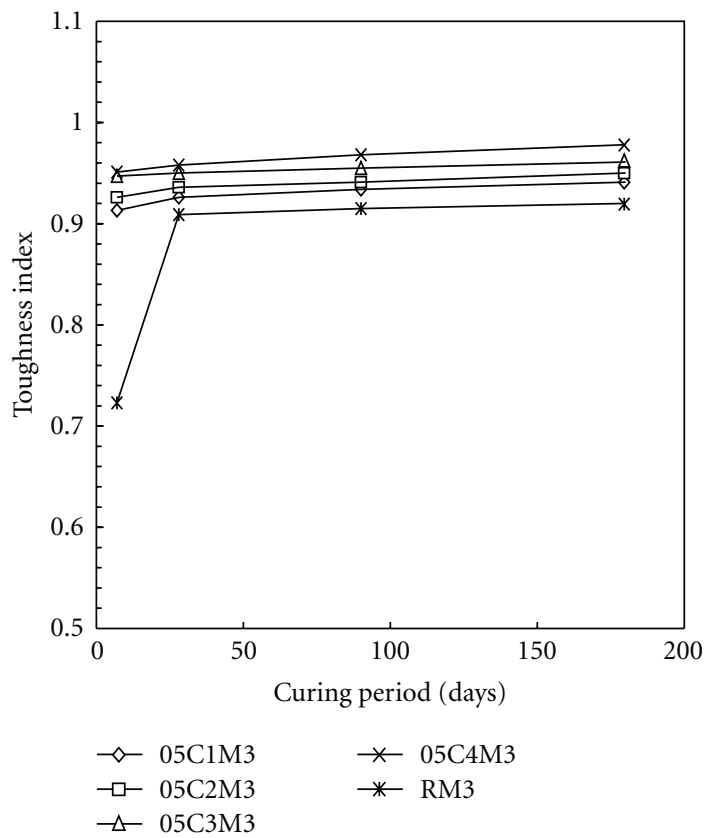

(c)

FIGURE 7: Variation of toughness index in tension with curing period of the reference mix with and without 5\% dry/treated tire chips cured with curing method (a) M1, (b) M2, and (c) M3.

specimen $05007 \mathrm{C} 1 \mathrm{M} 1$, the toughness index was 0.857 , which increased to 0.906 when the curing method was changed from M1 to M2. The value of toughness index of the same specimen further increased to 0.913 with the change in curing method to M3. Similar increase in toughness index was observed with other treated tire chips. A study of Figures 7(a), 7(b), and 7(c) further reveals an increase in toughness index with the increase in curing period. For example, for specimen $05007 \mathrm{C} 1 \mathrm{M} 1$, the toughness index was 0.857 , which increased to $0.863,0.884$ and 0.893 after 28,90 , and 180 days of curing, respectively. A similar increase in toughness index was observed with other treated tire chips and curing methods. A close examination of Figures $7(\mathrm{a}), 7(\mathrm{~b})$, and 7 (c) reveals an increase in the toughness index with the inclusion of $5 \%$ dry/treated tire chips in the reference mix. For example, the toughness index of R007M1 was 0.50 which increased to 0.857 with the inclusion of $5 \%$ dry tire chips in the reference mix. Similar increase in toughness index was 


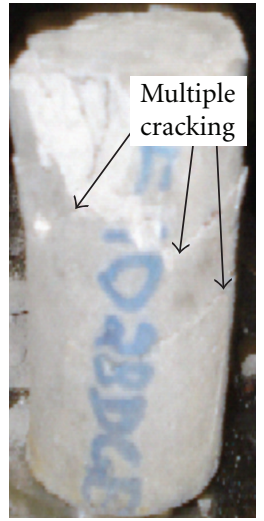

(a)

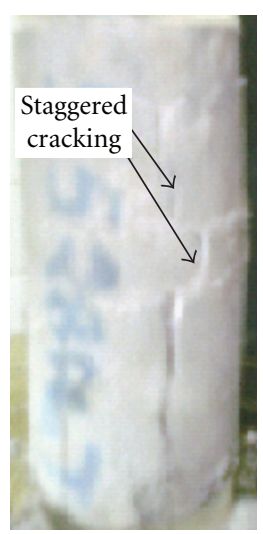

(b)

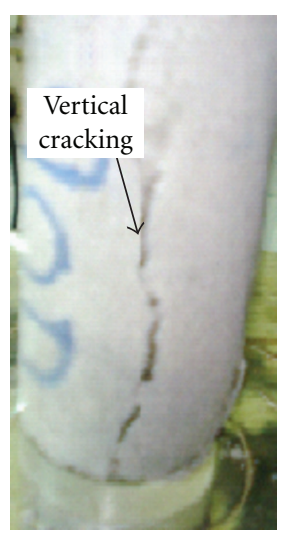

(c)

FIgURE 8: Cracking pattern of specimen under compression. (a) Multiple cracking in specimen containing tire chips. (b) Staggered cracking pattern in specimen containing tire chips. (c) Vertical cracking in reference mix.

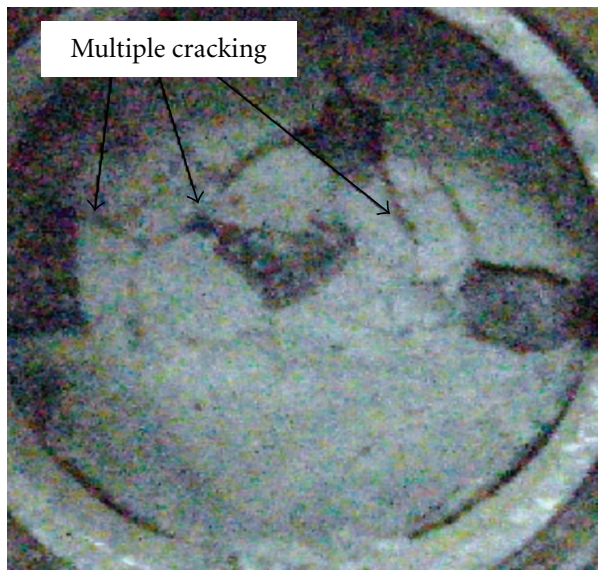

(a)

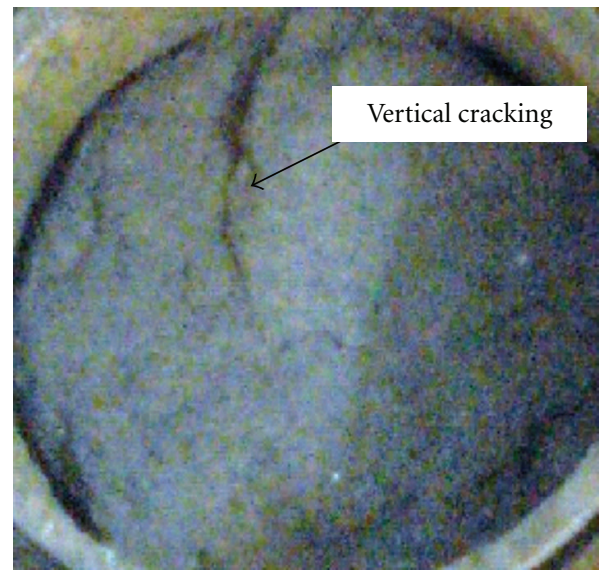

(b)

Figure 9: (a) Cracking pattern of specimen under tension. (a) Multiple cracking in specimen containing tire chips. (b) Vertical cracking in reference mix.

observed with the inclusion of other treated tire chips in the reference mix. Thus from the above discussion it can be concluded that inclusion of 5\% dry/treated tire chips increases the toughness characteristics of the reference mix in the postpeak region in tension. Further, toughness index of reference mix mixed with 5\% dry tire chips can be increased with the treatment provided on tire chips with carbon tetra chloride, sodium hydroxide and water. The toughness index was the highest with the inclusion of carbon tetra chloridetreated tire chips followed by sodium hydroxide and water. The toughness characteristics of reference mix mixed with $5 \%$ dry/treated tire chips also increases with change in the curing methods and with increase in the curing period.

\section{Discussion}

The compressive axial load, tensile load, compressive axial strain, and diametral strain of reference mix mixed with $5 \%$ dry tire chips increased with the treatment provided with carbon tetra chloride, sodium hydroxide, and water, and the increase was the highest with carbon tetra chloride followed by sodium hydroxide and water. Further, a decrease in compressive axial and tensile load was also observed due to inclusion of $5 \%$ dry/treated tire chips in reference mix. This decrease in the compressive axial and tensile load was attributed to the fact that tire chips act as soft particle within the composite. The tire chips also entrap air while mixing in the reference mix which causes formation of more voids and leads to the decrease in the compressive axial and tensile load. Beside this, the reference mix mixed with 5\% dry/treated tire chips has shown an improvement in the postpeak region both in compression and tension. This is attributed to the formation of multiple/staggered cracking pattern as evident from Figures 8 and 9. The lower Young's modulus of the tire chips in comparison to hardened reference mix causes dissimilar deformation which induces multiple/staggered cracking in the composite. This multiple/staggered cracking helps the specimen to bear the load after the failure. Contrary to this, no such multiple/staggered cracking pattern was 
observed in the reference mix without dry/treated tire chips and specimen failed catastrophically by development of a straight vertical crack as evident from Figures 8(c) and 9(b). Further, due to improved postpeak behavior of reference mix mixed with $5 \%$ dry/treated tire chips, an increase in toughness index was observed. Since reference mix mixed with $5 \%$ dry/treated tire chips has shown increased value of strain and toughness characteristics in compression and tension, potential use of this relatively new constructional material can be road pavement having light traffic. Further, the use of the composite material will also provide environmental motivation for providing a means of recycling large quantities of waste tire rubber along with the effective utilization of fly ash. However, more research is required to address the long-term durability, environmental concerns, effect of confining pressure on tension and compression behavior, and flexural strength for use in road pavement having light traffic.

\section{Conclusion}

In the present paper, reference mix containing fly ash $+8 \%$ lime $+0.9 \%$ gypsum was mixed with $5 \%$ dry/treated tire chips cured for 7 to 180 days by three different methods of curing. On the basis of the results of the experimental investigation and the discussions made in the earlier sections, the following conclusions can be drawn.

(1) The compressive axial and tensile load of the reference mix mixed with $5 \%$ dry tire chips increased with the increase in curing period, change in curing method, and the treatment provided on the tire chips. The increase was the highest with the inclusion of treated tire chips with carbon tetrachloride followed by sodium hydroxide and water, respectively as well as when cured in water-filled container followed by burlap and dessicator, respectively.

(2) The compressive axial and diametral strain of reference mix mixed with 5\% dry tire chip increases with treatment and was the highest with the treatment provided with carbon tetra chloride followed by sodium hydroxide and water. The compressive axial and diametral strain increased with the change in curing method and increase in curing period.

(3) The inclusion of $5 \%$ dry/treated tire chips in reference mix improves the postpeak behaviour in compression and tension.

(4) The inclusion of 5\% dry/treated tire chips in reference mix increases the toughness index and was the highest with the inclusion of carbon tetra chloride treated tire chips followed by sodium hydroxide and water, respectively. The toughness index of reference mix with and without tire chips increased with the change in curing method and was the highest when cured in water-filled container followed by burlap and dessicator, respectively. The toughness index of reference mix with and without tire chips increases with the increase in the curing period.

\section{References}

[1] G. V. Rao and R. K. Dutta, "Compressibility and strength behaviour of sand-tyre chip mixtures," Geotechnical and Geological Engineering, vol. 24, no. 3, pp. 711-724, 2006.

[2] S. R. Kaniraj and V. Gayathri, "Geotechnical behaviour of fly ash mixed with randomly oriented fiber inclusions," Geotextiles and Geomembranes, vol. 21, no. 3, pp. 123-149, 2003.

[3] P. J. Bosscher, T. B. Edil, and S. Kuraoka, "Design of highway embankments using tire chips," Journal of Geotechnical and Geoenvironmental Engineering, vol. 123, no. 4, pp. 295-304, 1997.

[4] D. E. B. Nightingale and W. P. Green, "An unsolved riddle: tire chips, two roadbeds, and spontaneous reactions," in ASTM STP 1275, M. A. Wasemiller and K. B. Hoddinott, Eds., pp. 265-285, Philadelphia, Pa, USA, 1997.

[5] T. C. Heimdahl and A. Drescher, "Elastic anisotropy of tire shreds," Journal of Geotechnical and Geoenvironmental Engineering, vol. 125, no. 5, pp. 383-389, 1999.

[6] P. S. H. Poh and B. B. Broms, "Slope stabilization using old rubber tires and geotextiles," Journal of Performance of Constructed Facilities, vol. 9, no. 1, pp. 76-79, 1995.

[7] V. O'Shaughnessy and V. K. Garga, "Tire-reinforced earthfillpart 2: pull-out behavior and reinforced slope design," Candian Geotechnical Journal, vol. 37, pp. 97-116, 2000.

[8] I. H. D. Sumanarathna, D. P. Mallawarctchie, and S. A. S. Kulathilaka, "Stabilization of slopes by anchored type retaining structures," in Proceedings of the 14th Internatinal Conference of Soil Mechanics and Foundation Engineering, pp. 1261-1264, New Delhi, India, 1997.

[9] N. Tatlisoz, C. Benson, and T. Edil, "Effect of fines on mechanical properties of soil-tire chip mixtures," in ASTM STP 1275, M. A. Wasemiller and K. B. Hoddinott, Eds., p. 93108, Philadelphia, Pa, USA, 1997.

[10] M. A. Allman and G. Simundic, "Testing of a retaining wall constructed of waste tires," in Proceeding of 3rd International Congress on Environmental Geotechnics, vol. 2, pp. 655-660, Lisbon, Portugal, 1998.

[11] J. H. Lee, R. Salgado, A. Bernal, and C. W. Lovell, "Shredded tires and rubber-sand as lightweight backfill," Journal of Geotechnical and Geoenvironmental Engineering, vol. 125, no. 2, pp. 132-141, 1999.

[12] V. K. Garga and V. O’Shaughnessy, “Tire-reinforced earthfillpart 1: construction of a test fill, performance, and retaining wall design," Canadian Geotechnical Journal, vol. 37, no. 1, pp. 75-96, 2000.

[13] T. Hall, "Reuse of shredded tire material for leachate collection system," in Proceedings of the 14th Annual Conference, pp. 367376, University of Wisconsin, 1991.

[14] I. Ahmed and C. Lovell, "Use of rubber tires in highway construction," in Proceedings of the Utilization of Waste Materials in Civil Engineering Construction, pp. 166-181, ASCE, New York, NY, USA, 1992.

[15] J. Park, J. Kim, and T. Edil, "Sorption capacity of shredded waste tires," in Proceedings of the International Symposium on Geotechnical Related to the Environment, pp. 341-348, A. Balkema, Rotterdam, The Netherlands, 1993.

[16] G. J. Foose, C. H. Benson, and P. J. Bosscher, "Sand reinforced with shredded waste tires," Journal of Geotechnical and Geoenvironmental Engineering, vol. 122, no. 9, pp. 760-767, 1996. 
[17] M. Tuncan, A. Cetin, A. Tuncan, and H. Koyuncu, "Assessment of waste tires and plastic on asphalt concrete pavement mixtures," in Proceedings of 3rd International Congress on Environmental Geotechnics, vol. 2, pp. 667-672, Lisbon, Portugal, 1998.

[18] D. N. Humphrey, L. E. Katz, and M. Blumenthal, "Water quality effects of tire chip fill placed above the groundwater table," in ASTM STP 1275, M. A. Wasemiller and K. B. Hoddinott, Eds., pp. 299-313, Philadelphia, Pa, USA, 1997.

[19] N. N. Eldin and A. B. Senouci, "Rubber-tire particles as concrete aggregate," Journal of Materials in Civil Engineering, vol. 5, no. 4, pp. 478-496, 1993.

[20] C. Bader, "Where will all the tires go?" Municipal Solid Waste Management, vol. 2, no. 7, pp. 26-30, 1992.

[21] P. J. Bosscher, T. B. Edil, and N. N. Eldin, "Construction and performance of a shredded waste-tire test embankment," Transportation Research Record 1345, Transportation Research Board, Washington, DC, USA, 1992.

[22] D. N. Humphrey and W. P. Manion, "Properties of tire chips for light weight fill: grouting, soil improvement and geosynthetics Grouting, soil improvement and geosynthetics," vol. 2, pp. 1344-1355, 1992.

[23] D. N. Humphrey and T. C. Sandford, "Tire chips as light weight subgrade fill and retaining wall backfill," in Proceedings of the Symposium on Recovery and Effective Reuse of Discarded Materials and By-products for Construction of Highway Facilities, pp. 5-99, Federal Highway Administration, Washington, DC, USA, 1993.

[24] D. N. Humphrey, T. C. Sandford, M. M. Cribbs, and W. P. Manion, "Shear strength and compressibility of tire chips for use as retaining wall backfill," Transportation Research Record 1422, Transportation Research Board, Washington, DC, USA, 1993.

[25] T. B. Edil and P. J. Bosscher, "Development of engineering criteria for shredded or whole tires in highway applications," Final Report GT-92-9, University of Wisconsin, Madison, Wis, USA.

[26] T. B. Edil and P. J. Bosscher, "Engineering properties of tire chips and soil mixtures," Geotechincal Testing Journal, vol. 17, no. 4, pp. 453-464, 1994.

[27] D. N. Humphrey and W. L. Nickels, "Tire chips as subgrade insulation and lightweight fill," in Proceedings of the 18th Annual Meeting of the Asphalt Recycling and Reclaiming Association, pp. 83-105, Annapolis, Md, USA, 1994.

[28] A. Drescher and D. E. Newcomb, "Development of design guidelines for use of shredded tires as a lightweight fill in road subgrade and retaining walls," Tech. Rep. MN/RC-94/04, Department of Transportation, St. Paul, Minn, USA, 1994.

[29] D. E. Newcomb and A. Drescher, "Engineering properties of shredded tires in lightweight fill applications," Transportation Research Record 1437, Transportation Research Board, , Washington, DC, USA, 1994.

[30] I. Ahmed, "Laboratory study on properties of rubber soils," Tech. Rep. FHWA/IN/JHRP-93/4, Purdue University, West Lafayette, Ind, USA, 1993.

[31] A. Bernal, R. Salgado, and C. Lovell, "Laboratory study on the use of tyre shreds and rubber-sand in backfills and reinforced soil applications," Final Report FHWA/IN/JHRP96, Purdue University, Indiana Department of Transportation, Joint Highway Research Project, West Lafayette, Ind, USA, 1996.
[32] S. Youwai and D. T. Bergado, "Strength and deformation characteristics of shredded rubber tire-sand mixtures," Canadian Geotechnical Journal, vol. 40, no. 2, pp. 254-264, 2003.

[33] D. T. Bergado, S. Youwai, and A. Rittirong, "Strength and deformation characteristics of flat and cubical rubber tyre chip-sand mixtures," Geotechnique, vol. 55, no. 8, pp. 603-606, 2005.

[34] M. Ghazavi and M. A. Sakhi, "Influence of optimized tire shreds on shear strength parameters of sand," International Journal of Geomechanics, vol. 5, no. 1, pp. 58-65, 2005.

[35] H. Cetin, F. Mustafa, and G. Osman, "Geotechnical properties of tire-cohesive clayey soil mixtures as a fill material," Engineering Geology, vol. 88, no. 1-2, pp. 110-120, 2006.

[36] R. K. Dutta and G. V. Rao, "Regression models for predicting the behaviour of sand mixed with tire chips," International Journal of Geotechnical Engineering, vol. 3, no. 1, pp. 51-63, 2009.

[37] T. Y. Chu, D. T. Davidson, W. L. Goecker, and Z. C. Moh, “Soil stabilization with lime fly ash mixtures: preliminary studies with silty and clayey soils," Highway Research Board Bulletin, vol. 108, pp. 102-112, 1955.

[38] S. Raymond, "Pulverized fuel ash as embankment material," Proceedings of the Institution of Civil Engineers, vol. 19, pp. 515-536, 1961.

[39] J. N. Jha, K. S. Gill, and A. K. Choudhary, "Effect of high fraction class F flyash on lime stabilization of soil," International Journal of Geotechnics and Environment, vol. 1, no. 2, pp. 105-128, 2009.

[40] A. M. DiGioia and W. L. Nuzzo, "Fly ash as structural fills," Journal of Power Division, vol. 98, no. 1, pp. 77-92, 1972.

[41] A. Xu and S. L. Sarkar, "Micro structural developments in high-volume fly ash cement system," Materials in Civil Engineering, vol. 1, pp. 117-136, 1994.

[42] S. S. Kim and B. S. Chun, "The study on a practical use of wasted coal fly ash for coastal reclamation," in Proceedings of the 13th ICSMFE, pp. 1607-1612, 1994.

[43] V. Kumar, "Key note address," in Proceedings of the $3 \mathrm{rd}$ International Conference on Fly Ash Utilisation and Disposal, New Delhi, India, 2003.

[44] C. J. Fawconnier and R. W. O. Korsten, "Ash fill in pillar design," The SAIMM Monograph Series, vol. 4, pp. 277-361, 1982.

[45] G. M. Petulanas, "High volume fly ash utilization projects in the US and Canada," Final Report CS-4446, EPRI, , Palo Alto, Calif, USA, 1988.

[46] A. Ghosh and C. Subbarao, "Microstructural development in fly ash modified with lime and gypsum," Journal of Materials in Civil Engineering, vol. 13, no. 1, pp. 65-70, 2001.

[47] A. Ghosh and C. Subbarao, "Tensile strength bearing ratio and slake durability of class F fly ash stabilized with lime and gypsum," Journal of Materials in Civil Engineering, vol. 18, no. 1, pp. 18-27, 2006.

[48] S. P. Guleria and R. K. Dutta, "Effect of addition of tirechips on the unconfined compressive strength of fly ash-limegypsum mixture," Journal of Materials in Civil Engineering. In press.

[49] M. H. Maher and P. N. Balaguru, "Properties of flowable highvolume fly ash-cement composite," Journal of Materials in Civil Engineering, vol. 5, no. 2, pp. 212-225, 1993.

[50] B. M. Das, S. C. Yen, and R. N. Dass, "Brazilian tensile strength test of lightly cemented sand," Canadian Geotechnical Journal, vol. 32, no. 1, pp. 166-171, 1995. 
[51] N. C. Consoli, P. D. M. Prietto, J. A. H. Carraro, and K. S. Heineck, "Behavior of compacted soil-fly ash-carbide lime mixtures," Journal of Geotechnical and Geoenvironmental Engineering, vol. 127, no. 9, pp. 774-782, 2001.

[52] K. Sobhan and M. Mashnad, "Mechanical stabilization of cemented soil-fly ash mixtures with recycled plastic strips," Journal of Environmental Engineering, vol. 129, no. 10, pp. 943947, 2003.

[53] A. Ghosh, Environmental and engineering characteristics of stabilized low lime fly ash, Ph.D. thesis, Indian Institute of Technology, Kharagpur, India, 1996.

[54] S. P. Guleria and R. K. Dutta, "Tensile strength of fly ash- lime-gypsum composite mixed with treated tyre chips," International Journal of Geotechnics and Environment, vol. 2, no. 2, pp. 71-87, 2010.

[55] S. P. Guleria and R. K. Dutta, "Effect of addition of tire chips on the unconfined compressive strength of fly ashlime-gypsum mixture," International Journal of Geotechnical Engineering. In press.

[56] Z. K. Khatib and F. M. Bayomy, "Rubberized Portland cement concrete," Journal of Materials in Civil Engineering, vol. 11, no. 3, pp. 206-213, 1999.

[57] N. Segre and I. Joekes, "Use of tire rubber particles as addition to cement paste," Cement and Concrete Research, vol. 30, no. 9, pp. 1421-1425, 2000.

[58] R. S. Rollings, J. Pete Burkes, and M. P. Rollings, "Sulfate attack on cement-stabilized sand," Journal of Geotechnical and Geoenvironmental Engineering, vol. 125, no. 5, pp. 364-372, 1999.

[59] A. Ghosh and C. Subbarao, "Hydraulic conductivity and leachate characteristics of stabilized fly ash," Environmental Engineering, vol. 124, no. 9, pp. 812-820, 1998. 

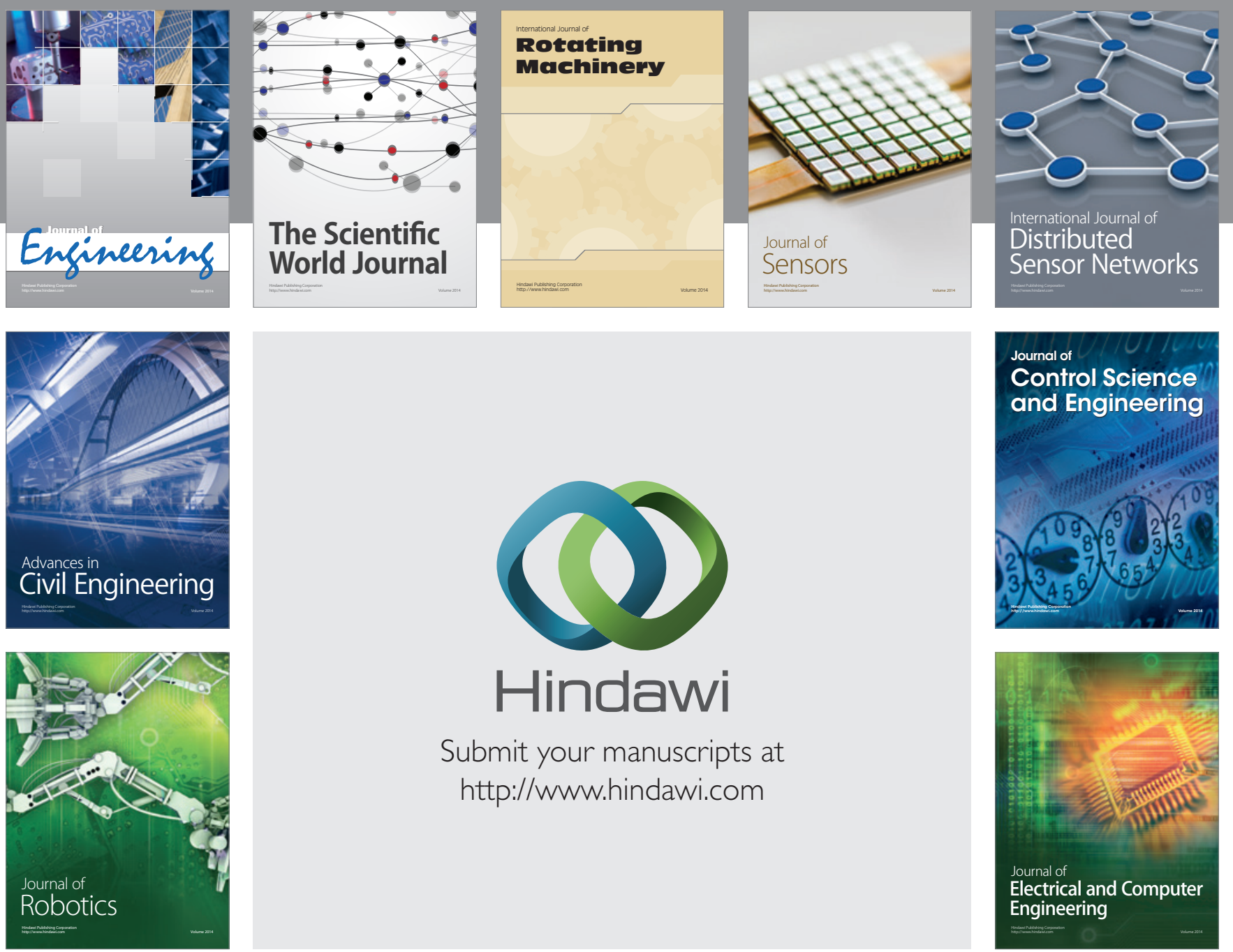

Submit your manuscripts at

http://www.hindawi.com
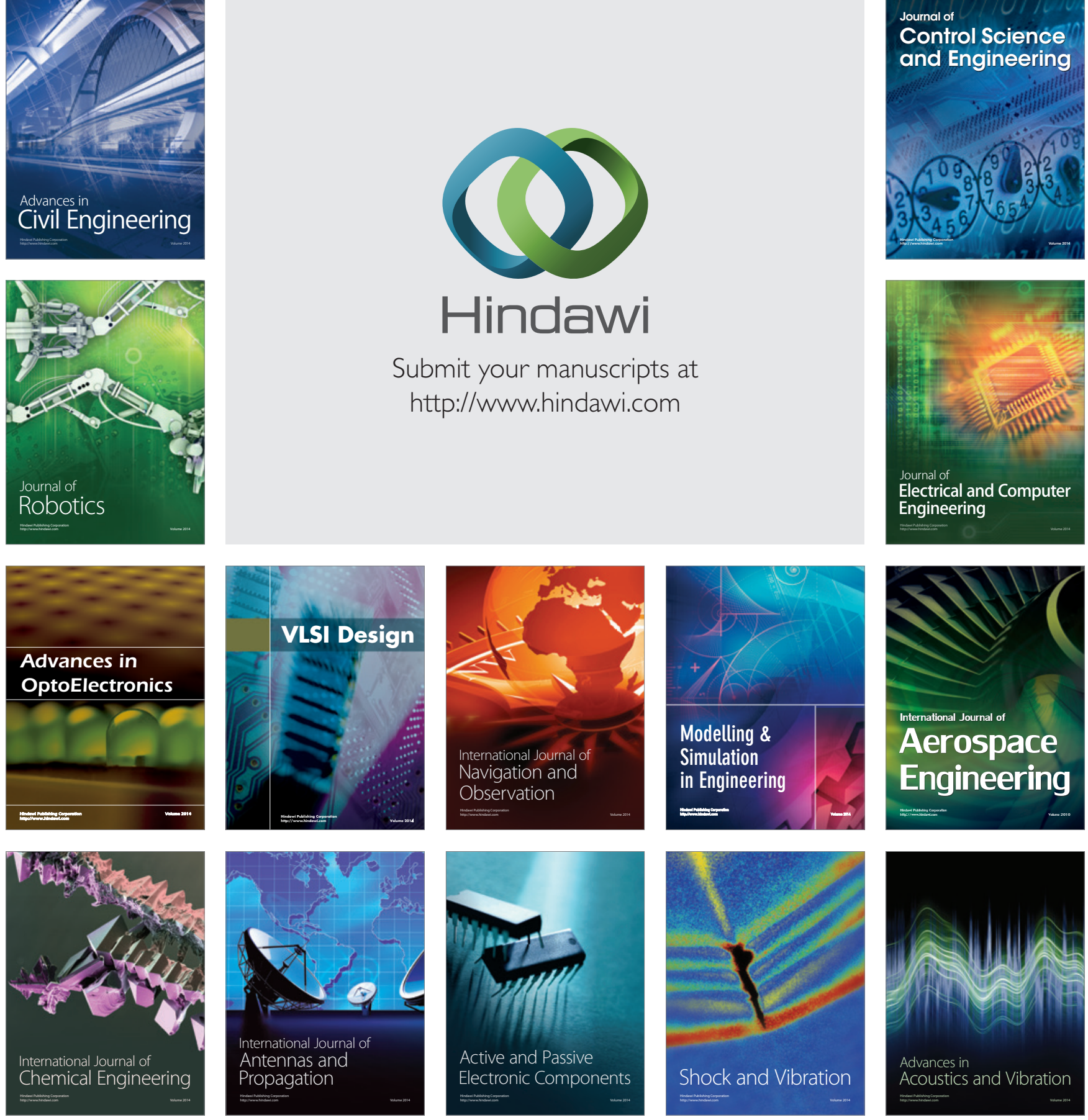